\title{
Lixivaptan reduces volume overload in patients with heart failure
}

The vasopressin $\mathrm{V}_{2}$ receptor antagonist lixivaptan is well tolerated and reduces fluid retention in patients with decompensated heart failure (HF), according to the results of a phase II, multicenter clinical trial conducted in the USA. Diuretics are commonly used to treat volume overload in these patients, but can cause electrolyte imbalance, neurohormonal activation, and impaired renal function. Vasopressin receptor antagonists are novel class of agents that might achieve effective volume unloading without these adverse effects.

Investigators randomly allocated 170 patients with $\mathrm{HF}$ and volume overload to receive lixivaptan $100 \mathrm{mg}(n=111)$ or placebo $(n=59)$ in addition to standard therapy (most-commonly including loop diuretics, $88.8 \%$; $\beta$-blockers, $58.2 \%$; and angiotensin-converting-enzyme inhibitors, 45.3\%). A significant decrease in body weight occurred between baseline and day 1 in patients treated with lixivaptan compared with those receiving placebo. This difference was maintained over the 8-week period of treatment during the trial, and occurred irrespective of baseline left ventricular ejection fraction ( $<40 \%$ or $\geq 40 \%)$. Lixivaptan improved orthopnea and dyspnea, and was well tolerated by the patients.

Further study is required to address the limitations of this trial, which had a high drop-out rate of $23 \%$, and in which neither potential neurohormonal and hemodynamic effects nor clinical outcomes were evaluated. Furthermore, the possible merits of a variable-dose regimen of lixivaptan were not assessed in this fixed-dose trial.

Gregory B. Lim

Original article Ghali, J. K. et al. The efficacy and safety of lixivaptan in outpatients with heart failure and volume overload: results of a multicentre, randomized, doubleblind, placebo-controlled, parallel-group study. Eur. J. Heart Fail. doi:10.1093/eurjhf/hfs051 